\title{
Crohn's disease in the elderly
}

\author{
P J FABRICIUS, S N GYDE, P SHOULER, M R B KEIGHLEY, \\ J ALEXANDER-WILliAMS, AND R N ALLAN
}

From the Gastroenterology Unit, General Hospital, Birmingham

SUMmaRY The natural history of Crohn's disease in 47 patients, 60 years of age or older at the time of diagnosis has been defined, and their clinical management and long term prognosis reviewed. Distal colonic involvement is common in this group while extensive colonic and diffuse small bowel disease is rare. Distal colonic involvement usually carries a good prognosis except for those few patients who present with perforation which accounts for most of the disease related mortality. The pattern of distal ileal disease is similar to that observed in the younger patients except for the acute nature of symptoms at first presentation, and the low recurrence rates after initial surgical resection.

Because the prevalence of inflammatory bowel disease is highest in young adults, the specific problem in the older patient has received little attention $^{1-9}$ and most reports have been confined to patients with ulcerative colitis. ${ }^{1-7}$ One study only included six patients with Crohn's disease diagnosed over 50 years of age ${ }^{8}$ while the other analysed the outcome of 64 patients with late onset inflammatory bowel disease of whom 30 had Crohn's disease. ${ }^{9}$ Two further reports have reviewed the specific problem of Crohn's disease of the distal large bowel: a particularly common site of macroscopic disease in the older patient. ${ }^{10} 11$

In this study we have analysed the natural history, clinical management and long term prognosis of 47 patients with Crohn's disease who were 60 years of age or older at the time of diagnosis.

\section{Methods}

PATIENTS

Forty seven patients $(M=25)$ with Crohn's disease who were 60 years of age or older at diagnosis were identified among a series of more than 600 patients under long term review between 1944-1983. The mean age at onset of symptoms was 66.1 years (range 49-92 years). The mean age at diagnosis was 67.7 years (range 60-92 years) and the mean interval between onset and diagnosis 1.6 years (range 1 month-15 years).

The diagnosis of Crohn's disease was established

Address for correspondence: Dr R N Allan, Gastroenterology Unit, General Hospital, Steelhouse Lane, Birmingham B4 6NH.

Received for publication 15 June 1984 by histopathological examination of a resected specimen $(n=25)$ by combined radiological assessment and histopathological examination of colonic biopsies $(n=13)$ or by radiological evidence alone $(n=10)$. In this last group five also had perianal disease and three others radiological changes in the distal ileum. A small number of cases were diagnosed either at laparotomy $(n=2)$ or on biopsy alone $(\mathrm{n}=2)$.

The distribution of macroscopic Crohn's disease in the older patient is compared with patients below 60 years of age at diagnosis in Table 1 . The incidence of distal ileal \pm right colon disease in the two groups is similar ( $61 \%$ and $48 \%$ respectively). Distal colonic Crohn's disease is commoner in the older patients $(40 \%$ vs $6 \%)$. Extensive colonic Crohn's disease is commoner in younger patients ( $27 \%$ vs $4 \%$ ). Diffuse involvement of the small bowel is uncommon in both groups.

The overall outcome is summarised in Table 2 .

DISTAL ILEAL DISEASE

Twenty two patients $(M=10)$ had distal ileal disease. The mean age at onset of symptoms was 65.9 years and 68.2 years at diagnosis. The mean interval between onset of symptoms and diagnosis was $2 \cdot 3$ years (range 0-14 years). The interval was less than a year in 14 of these patients. Of the 11 patients who had a barium enema examination four had evidence of associated diverticular disease.

\section{Presentation}

Although symptoms had often been present for some time, an acute exacerbation usually 
Table 1 Distribution of macroscopic Crohn'a disease at diagnosis in patients under and over 60 years of age (\%)

\begin{tabular}{lcc}
\hline & $<60$ years & $>60$ years \\
\hline Diffuse small bowel & 5.6 & 0 \\
Ileum \pm right colon & 61.2 & 46.8 \\
Extensive colonic involvement & 26.5 & 4.2 \\
Distal colon & 5.8 & 40.4 \\
Other sites & 1.3 & 6.4 \\
\hline
\end{tabular}

precipitated the patients first hospital attendance. Fourteen patients presented with obstructive symptoms or peritonitis requiring either emergency or early laparotomy. One patient presented with severe anaemia: the others with abdominal pain, diarrhoea, and weight loss.

\section{Medical management}

As most patients presented acutely and underwent early laparotomy, specific medical treatment played little part in their management. Only one patient received sulphasalazine and two corticosteroid therapy.

\section{Surgical treatment}

During the period of review 19 of the 22 patients underwent laparotomy of whom 17 had a resection. Ten of the laparotomies were carried out within 12 months of the onset of symptoms. The commonest indications were emergency laparotomy for obstruction or peritonitis $(n=8)$ or laparotomy to exclude carcinoma which had been suspected in patients with radiological deformity of the ileocaecal area $(n=6)$.

\section{Recurrent disease}

The mean interval of follow up from onset of symptoms was 12.5 years and 10.9 years from diagnosis. Despite the long period of follow up only two patients have developed radiological evidence of recurrent disease, and no patient has had a second resection.

\section{Mortality}

Eight patients in this group died during the period of review although only two were related to their underlying Crohn's disease. One died postoperatively after surgical treatment of an ileal perforation, and the other died of peritonitis secondary to a gangrenous strangulated hernia.

\section{Current status}

All 14 survivors, including the two patients with radiological evidence of recurrent disease, are well and symptom free.

\section{CROHN'S DISEASE OF THE LARGE INTESTINE \\ Patients}

There were 22 patients $(M=12)$ whose mean age at the onset of symptoms was $66 \cdot 2$ years and mean age at diagnosis 67.4 years. The mean interval of follow up from onset of symptoms was 6.8 years and 5.6 years from diagnosis.

Table 2 Summary of the outcome of Crohn's disease in the older patient

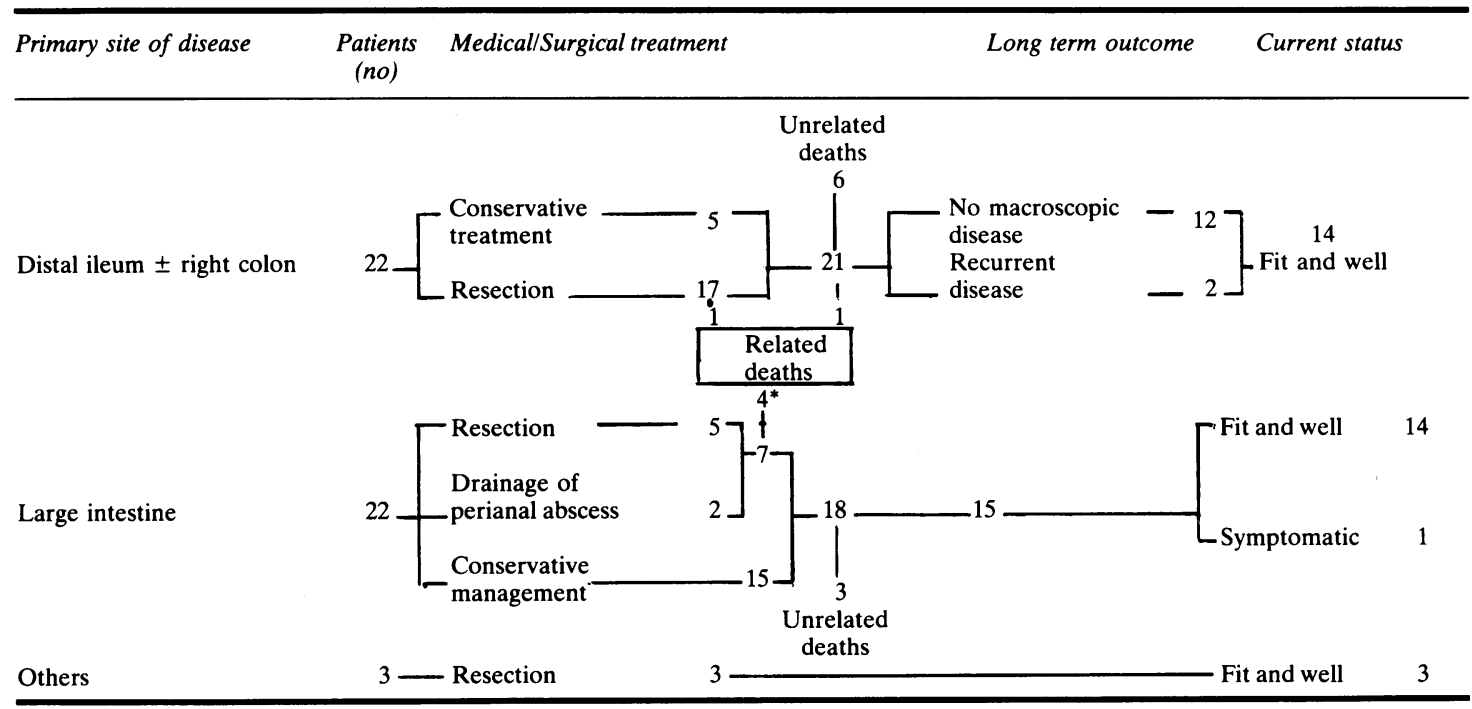

*Two moribund at the time of laparotomy 


\section{Presentation}

At presentation 19 patients had left sided disease (which in three extended distally to include the rectum), two had total colonic disease without rectal involvement and one had segmental disease confined to the transverse colon. Only two patients with left sided disease progressed to extensive colonic involvement. The diagnosis was established by histopathological examination of resected specimens in five patients and from the radiological appearances and biopsy material in 13 (of whom four also had perianal disease). In two cases each the diagnosis was based on radiological appearances or rectal biopsy. Uncomplicated diverticular disease was present in 13 of the 22 patients with Crohn's colitis and in all but one of the patients this was associated with left sided disease. Eight patients have perianal disease.

The initial radiological assessment was normal in three patients but repeat examinations during the period of follow up revealed changes characteristic of Crohn's colitis.

Nearly all patients presented with diarrhoea often associated with bleeding, weight loss, or abdominal pain. In one patient the diagnosis was made after emergency laparotomy for a perforated sigmoid colon and in another there was histological evidence of Crohn's disease in the surgical specimen after resection of a rectovaginal fistula thought initially to be associated with diverticular disease alone.

\section{Medical management}

Fifteen of the 22 patients were treated conservatively and in two others surgical treatment was confined to drainage of a perianal or ischiorectal abscess.

\section{Surgical treatment}

Five patients underwent laparotomy, three for colonic perforations of whom two died in the early postoperative period.

\section{Mortality}

Seven patients died, three of unrelated causes (carcinoma of oesophagus, carcinoma of bronchus, fractured femur followed by cerebrovascular accident). Four deaths were related to the underlying disease; two patients presented with perforation and died in the early postoperative phase (see above), one patient died of septicaemia after drainage of an ischiorectal abscess and a fourth was a late death after total colectomy. Two of the four patients who died were receiving corticosteroid therapy.
Medical treatment

Seven patients have been treated with corticosteroids of whom five also had sulphasalazine. Three further patients have been treated with a combination of sulphasalazine and local steroid enemas.

\section{Current status}

Of the 15 survivors all but one are fit and well. The exception is a patient with repeated relapses who is not fit for surgical treatment because of her age and associated cardiovascular problems.

\section{Other sites}

Three patients had disease in the stomach, jejunum, and mid-ileum respectively. All have had surgical treatment and are now well.

Diffuse small bowel disease

Diffuse small bowel disease was not encountered in this older age group; the incidence in the series overall was $5 \%$ and $21 \%$ in children under 16 years of age. ${ }^{13}$

\section{Discussion}

Crohn's disease in the older patient is uncommon. In individual series the proportion of patients with Crohn's disease over the age of 60 years at diagnosis varies between 1 and $20 \% .814-16$

In this consecutive series $8 \%$ of the patients were 60 years or more when their Crohn's disease was diagnosed.

A number of reports have suggested a female predominance in older patients with Crohn's disease $^{9151718}$ but in this series the sex incidence was similar.

It has been suggested that ileal disease is rare in the older patient ${ }^{9}$ but we, like Tchirkow and his colleagues ${ }^{17}$ found that the incidence of ileal disease is similar to that observed in the general population.

We agree with Carr and Schofield ${ }^{9}$ that disease in the large intestine is usually confined to the rectum and sigmoid colon although occasional examples of extensive colonic involvement have been reported. ${ }^{17}$

The onset of symptoms in younger patients with distal ileal Crohn's disease is characteristically gradual ${ }^{19}$ and this pattern has also been observed in older patients. ${ }^{17}$ We found, however, that while symptoms may have been present for some time, the commonest mode of presentation was acutely with peritonitis or an obstructive episode requiring early laparotomy. Early laparotomy was needed when ileocaecal cancer could not be excluded on radiological grounds alone. Because of the acute presentation, specific medical treatment played little 
part in their management. Despite their age the patients withstood surgical treatment well, and despite the long period of follow up only two patients have developed radiological evidence of recurrent disease. This supports the observation of Puntis and his colleagues ${ }^{13}$ that the recurrence rate after resection for distal ileal disease is inversely related to age.

The common mode of presentation in the older patient with Crohn's disease was a change of bowel habit with rectal bleeding and weight loss. It needs emphasising that the initial radiological assessment in the symptomatic patient may be normal so that the radiological examination should be repeated if symptoms persist. Although rare, acute perforation is an important complication because it is associated with a high morbidity and mortality.

Most symptomatic patients responded to. intravenous fluid replacement and blood transfusion and corticosteroid therapy for the severely ill. Only five of the 22 patients have needed surgical treatment. Nearly half the patients reviewed by Ritchie and Lennard-Jones had undergone surgical treatment ${ }^{10}$ but this was a selected series of patients largely referred for surgical treatment. The authors commented that patients first seen in their own unit only rarely required surgical treatment.

Carr and Schofield ${ }^{9}$ distinguished Crohn's proctitis which was associated with an excellent prognosis from those with left sided colitis who often had recurrent and troublesome symptoms. Nearly all patients in this series had Crohn's disease involving the left side of the colon, usually with rectal sparing. We cannot comment on the incidence of recurrent disease in Crohn's colitis in the older patient because so few patients required surgical treatment.

Rather more than half our patients with Crohn's colitis had associated diverticular disease, a similar proportion to that reported by Ritchie and LennardJones. ${ }^{10}$ This prevalence is probably no higher than that to be expected in the general population at this age. Occasionally symptoms are ascribed to the diverticular disease and the associated Crohn's disease is overlooked initially. ${ }^{17}$

The contribution of intestinal ischaemia to the natural history of the disease in the older patient though is uncertain none of the patients undergoing resection had histological evidence of ischaemic colitis.

Colonoscopy might play a useful role in those patients with positive symptoms and an initially normal radiological examination and also in those patients where the radiological findings cannot clearly be distinguished between ileocaecal Crohn's disease and caecal carcinoma. ${ }^{20}$
Of the 47 patients there were six related and nine unrelated deaths. Thirty two patients are still alive. All 14 patients with distal ileal disease are fit and well and only two have radiological evidence of recurrent disease. Of the 15 patients with colonic Crohn's disease all but one are well. The other three patients who had resections at other sites are also well and symptom free.

Although Crohn's disease characteristically affects younger patients it does occur in the older patient when it presents special problems, both in diagnosis and management. Surgical intervention is needed no more frequently than in the younger patient and the prognosis in most patients is excellent.

\section{References}

1 Banks BM and Klayman ML. Idiopathic ulcerative colitis beginning after the age of 50. N Engl J Med 1953; 249; 91-6

2 Bercovitz ZT. Ulcerative colitis in older patients. Gastroenterology 1960; 39: 28-33.

3 Law DH, Steinburg H, Sleisinger MH. Ulcerative colitis with onset after the age of 50. Gastroenterology 1961; 41: 457-64.

4 Diethelm AG, Nickel WF, Wantz GR. Ulcerative colitis in the elderly patients. Surg Gynecol Obstet 1968; 126: 1223-9.

5 Earle E, Rowe RJ. Ulcerative disease of the large intestine in patients more than 50 years old. Dis Colon Rectum 1972; 15: 33-40.

6 Toghill PJ, Benton PW. Ulcerative colitis in elderly patients Gerontol Clin 1973; 15: 65-73.

7 Margolis IB, Faror S, Earlyu MH et al. Megacolon in the elderly - ischemic or inflammatory? Ann Surg 1979; 190: $40-4$.

8 Rusch V, Simonovitz DA. Crohn's disease in the older patient. Surg Gynecol Obstet 1980; 150: 184-6.

9 Carr N, Schofield PF. Inflammatory bowel disease in the older patient. Br J Surg 1982; 69: 223-5.

10 Ritchie JK, Lennard-Jones JE. Crohn's disease of the distal large bowel. Gastroenterology 1976; 11: 433-6.

11 Williams NS, MacFie J, Celestin LR. Ano-rectal Crohn's disease. Br J Surg 1979; 66: 743-8.

12 Prior P, Gyde SN, Cooke WT, Waterhouse JAH, Allan RN. Mortality in Crohn's disease. Gastroenterology 1981; 80: 307-12.

13 Puntis J, McNeish AS, Allan RN. Long-term prognosis of Crohn's disease with onset in childhood and adolescence. Gut 1984; 25: 329-36.

14 Rogers BHG, Clark LM, Kirsner JB. The epidemiologic and demographic characteristics of inflammatory bowel disease; an analysis of a computerized file of 1400 patients. J Chronic Dis 1971; 24: 743-73.

15 Myren J, Gjone E, Hertzberg JN, Rygvold O, Semb 
LS, Fretheim B. Epidemiology of ulcerative colitis and regional enterocolitis (Crohn's disease) in Norway. Scand J Gastroenterol 1971; 6: 511-4.

16 Goligher JC. Crohn's disease (granulomatous enteritis). In: Goligher JC. Surgery of the anus, rectum and colon. 4th ed. London: Bailliere Tindall, 1980: 827-57.

17 Tchirkow G, Lavery IC, Fazio VW. Crohn's disease in the elderly. Dis Colon Rectum 1983; 26: 177-81.

18 Truelove SC, Pena AS. Course and prognosis of Crohn's disease. Gut 1976; 17: 192-201.

19 Higgens CS, Allan RN. Crohn's disease of the distal ileum. Gut 1980; 21: 933-40.

20 Waye JD, Hunt RH. Colonoscopic diagnosis of inflammatory bowel disease: Surg Clin North Am 1982; 62: 905-13. 